\title{
EDITORIAL
}

\section{A Rainbow Paper - Tackling inequalities, a neo-liberal order in a world after Corona}

\begin{abstract}
The COVID-19 pandemic has exposed the devastating impact of inequalities that have plagued societies for generations. The timing of the events spiralling from the unlawful killing of an apparently innocent black man in the United States of America, led to an uprising of sorts across many countries. It touched the psyche of the people in the UK and came at a time when the British Association of Physicians of Indian origin reaches it 25th anniversary (1996-2021). One of the fundamental visions and values that the organisation was created on, was to promote excellence through equality and diversity. Therefore in its silver jubilee year, BAPIO launches an over-arching Alliance for Equality in Healthcare Professions. The Alliance is tasked to conduct a review of the evidence of differential attainment across the spectrum of healthcare careers, engage with stakeholders from the grassroots to the responsible organisations and finally generate an expert consensus on recommendations for the changes necessary to tackle such inequalities.
\end{abstract}

Keywords

BAME, Health inequalities, differential attainment
Indranil Chakravorty FRCP PhD, JS Bamrah FRCPsych \& Ramesh Mehta MD FRCPCH OBE

BAPIO Institute for Health Research, Bedford, UK Bapio.co.uk/bihr

Correspondence to: Indranil.chakravorty@nhs.net

DOI: $10.38192 / 13.3 .14$

Article information

Submitted 06.08.2020

Published 06.08.2020

Open Access- Creative commons Licence CC-BY-ND 4.0

\section{Introduction}

Twenty twenty, the year that may turn out to be one of the most transformative in the history of the modern world. The world as we know it, is changing. Economist and nobel laureate Amartya Sen, believes that the COVID-19 pandemic has inadvertently exposed the cracks in the liberal values of society, and this seismic event has created the conditions among the 'common people' for increased awareness of the vast inequalities that have existed for centuries. He cites an example in the events unfolding and gaining momentum following the brutal killing of George Floyd in the form of the 'BlackLivesMatter' movement. (1) (2) The recognition of the inequalities spread to many countries including the United Kingdom, where there were widely publicised desecration of public statues of controversial individuals, led by the common public, most notably the toppling of the statue of Edward Colston, a 17th century slave trader from the Royal African Company. (3) Sen, argues that it is sometimes easier to change laws but unless there is public awakening, wider recognition and a willingness to change from within, there is little hope of changing society.

Inequalities exist in every walk of life, in every profession and affect us all and more often than not, result in substantial loss of life and livelihood to the individual with significant social and economic cost to societies. In matters of health, the World Health Organisation describes inequities in the health status and distribution of resources between populations determined by how we are born, live, work and age. (3) What the COVID-19 pandemic has also done is to effectively expose to the public the stark inequalities that have existed for centuries, 
consistently recognised by policy makers, epidemiologists and scientists but not tackled on an organisational or governmental level (4). COVID-19 is profound in how it has affected people differently. In the early days of the pandemic when more homogeneous societies in the far east were experiencing the surge of cases, this inequity of how SARS-CoV-2 affected people based on their non-biological factors was not apparent. When the early figures were analysed in Europe the narrative was still based on factors such as obesity, advanced age and comorbidities.

It is only with the arrival of the pandemic in the UK and United States of America, that a new phenomenon of differential outcomes based on race or ethnicity became clear. What COVID-19 related early deaths has done is expose the inequalities that exist is how organisations deal with their staff based on factors other than their ability. The brutal message from the faces of healthcare staff who had died from COVID-19 was that of the colour of their skin. It took several more weeks and the work of organisations such as BAPIO that the country and its leaders recognised that all the poor outcomes that were being so consistently documented in people of Black, Asian and Minority Ethnic (BAME) groups were not attributable to them as individuals but to how the state and the system treated them. (5)

Colour, race and ethnicity are a few of the many facets of an unequal society which are recognised in all professions, but the mortality and morbidity data from COVID made them much more clear and transparent among health and care professionals. The Workplace Race Equality Standards (WRES) were established in the UK by the NHS equality and diversity council in 2014, and since 2015, all NHS Trusts have a legal duty to report their results against the 9 different standards. (6) However, the data from WRES in 2019 show little change in the levels of inequality over the previous 5 years since the standards were established. Clearly, more needs to be done and the NHS's first People Officer Prerana Issar, expresses her impatience at the pace of change, extolling the virtue of having the 'right culture' through the NHS People Plan (2020/21). A culture where people have the space and the ability to speak up especially about patient outcomes, where they get the development and career progression that they want and where there's a sense of belonging to the team that they work in. In essence, where they are valued and treated with fairness and equality. (7)

The story of differential attainment (DA) in healthcare professions is no different. Doctors from ethnic minority backgrounds face disadvantage throughout their careers, despite being selected for high academic achievement, end up performing worse on average than their white counterparts during education and training. Differential attainment appears at medical school and persists after qualification. As a result, ethnic minority graduates of UK medical schools have worse outcomes during recruitment for foundation, specialty training, and consultant posts; are more likely to fail examinations; and progress more slowly through training even when exam failure has been accounted for. Differential attainment is a difference in average group performance, not individual performance. (8) It is far worse for doctors who have their primary medical qualification in countries outside of the UK. It is not a phenomenon exclusive to the UK, but it is recognised in other countries where there is a large proportion of international medical graduates like the USA and Australia. A similar phenomenon is recognised in referral to the regulators, in how doctors are treated within organisational disciplinary processes and by the regulatory bodies. Fundamentally, this phenomenon exists not due to individual factors but organisational and societal disparities in cultures, support, attitudes and in many cases overt or covert racism. (8)

In 1996, the British Association of Physicians of Indian Origin (BAPIO) was conceived and created to address the vast inequalities that existed in access to career progression, unfair handling of disciplinary procedures and more importantly to support and mentor doctors from the Indian subcontinent, who were a substantial proportion of the workforce of the UK National Health Service. (9) In the quarter century of its existence, BAPIO has grown to be a significant influencer in supporting several other voluntary healthcare professional bodies, shaping organisational and governmental policy as well as expanding its remit to include all healthcare professions and mutually supportive partnerships with key institutions in matters of health including the General Medical Council, Medical Royal Colleges and Health Education England. 
BAPIO has been steadfast in taking seriously its responsibility to the fundamental principles of equality. In 2013-14, BAPIO took the Royal College of General Practitioners (RCGP) to court on its failure to act on the differential attainment of BAME and IMG doctors in the clinical skills assessment. The RCGP stated that it would take further action to support trainees who fail the MRCGP exam, after a High Court judge said 'the time has come to act' on differentials in the pass rates between white and non-white candidates. Although, Mr Justice Mitting found in favour of the RCGP, adding that the clinical skills assessment was a 'proportional' way of deciding who can practise as a General Practitioner, despite differences between the pass rates of white and non-white medical graduates, however, the court did say that the time has come' for the RCGP to address the differentials in the pass rates. He said that the claim - made by the British Association of Physicians of Indian Origin - was made in 'good faith by an organisation acting in the best interests of the public', adding that BAPIO had 'achieved, if not a legal success, then a moral success'.(10)

It has been over 5 years since the landmark judgement and the GMC report on health of medical education and progress in tackling DA, still highlights the significant and persistent disparities that continue to tarnish the image of a caring, fair culture within the 'caring profession'. $(11,12)$ The causes of DA are complex and often difficult to disentangle and in many cases data is limited. Organisations responsible for education and training have variable engagement, understanding and motivation to explore these differences and make a positive change. There are some clear leaders in this area and the Royal College of Physicians (RCP) has been a trailblazer in this field. Professor Andrew Goddard, the current President of the RCP London, reiterates his commitment,

'There is no room for complacency, as leaders it is our responsibility to do better. Our renewed focus starts today by asking all the leaders in our organisation to have conversations with the staff and members they work with to draw attention to this and to our commitment to ensure that the RCP is doing everything it can to eradicate racism and structural inequalities'. $(13,14)$

BAPIO agrees with the sentiment expressed by Professor Goddard. What the COVID-19 pandemic and the \#BlackLivesMatter campaign have highlighted to the broader society is that such disparities in access to universal health and education must be rooted out to establish fairness and equality, and that a caring and nurturing culture is fundamental to our values. BAPIO approaches its silver jubilee year in 2021, and at this opportune time is committed to establishing a milestone in the journey of tackling differential attainment. Through a series of thematic reviews, roundtables and consensus workshops, BAPIO will engage with grassroots, experts and stakeholders collaboratively creating an 'Alliance to tackle inequalities in healthcare professions'.

This alliance will produce a seminal document as a first step in creating an organisational change laboratory process to transform medical education, training and practice supporting the fundamental principles of the NHS People Plan. There was much debate on what the team should call this document. Many were uncomfortable with the connotations of the traditional descriptors such as 'white paper', 'green paper' and finally the eureka moment came from one of the team (Dr Sunil Daga, a Nephrologist from Leeds, UK) who suggested the innovative term, 'rainbow paper'. Although the establishment may not be ready to accept the term 'rainbow paper' just yet, we believe the society certainly is.

Healthcare professionals have always been quick to accept innovation and change when the evidence is robustly presented. It is therefore the responsibility of the 'Alliance' to review the evidence, understand the impact and implications working closely with those who have 'lived experiences', deliberate with the experts and lead the way.

In this issue of Sushruta Journal of Health Policy, the alliance team present the concept, framework and terms of reference of the 'rainbow paper' 'Bridging the Gap'.

The work starts now and we are excited to lead the ever growing members of the 'Alliance for tackling differential attainment in healthcare professions'. (14) It is your time for reckoning too if you care passionately about equity and equality in the health and social care systems, to join up. Individually we can make a collective difference. 


\section{References}

1. Chomsky and Sen want neo-liberal order thrown off its perch post COVID [Internet]. OnManorama. [cited 2020 Aug 6]. Available from: https://www.onmanorama.com/news/kerala/ 2020/06/26/noam-chomsky-amartya-sen-onblm-movement-covid-19-kerala-dialogue.html

2. Black Lives Matter. In: Wikipedia [Internet]. 2020 [cited 2020 Aug 6]. Available from: https://en.wikipedia.org/w/index.php?title=Bl ack_Lives_Matter\&oldid=971334380

3. WHO $\mid 10$ facts on health inequities and their causes [Internet]. WHO. World Health Organization; [cited 2020 Aug 6]. Available from:

http://www.who.int/features/factfiles/health_ inequities/en/

4. The NHS is 72 this year, covid-19 has taught us some tough lessons [Internet]. The BMJ. 2020 [cited 2020 Aug 6]. Available from: https://blogs.bmj.com/bmj/2020/07/31/thenhs-is-72-this-year-covid-19-has-taught-ussome-tough-lessons/

5. BAPIO sends letter to NHS employers regarding COVID-19: Disproportionate high mortality rates in BAME health and social care (HSCW) workers [Internet]. BAPIO Training Academy (BTA). 2020 [cited 2020 May 24]. Available from: https://www.bapiotrainingacademy.com/bapi o-sends-letter-to-nhs-employers-regardingcovid-19-disproportionate-high-mortalityrates-in-bame-health-and-social-care-hscwworkers/

6. NHS England » NHS Workforce Race Equality Standard [Internet]. [cited 2020 Aug 6]. Available from: https://www.england.nhs.uk/about/equality/ equality-hub/equality-standard/

7. Impatient for change: Prerana Issar on leadership and the NHS workforce [Internet]. The King's Fund. [cited 2020 Aug 6]. Available from: https://www.kingsfund.org.uk/audiovideo/podcast/prerana-issar-leadership-nhsworkforce

8. Linton S. Taking the difference out of attainment. BMJ [Internet]. 2020 Feb 12 [cited 2020 Jul 8];368. Available from: https://www.bmj.com/content/368/bmj.m43 8

9. British Association of Physicians of Indian Origin. In: Wikipedia [Internet]. 2020 [cited 2020 Aug 6]. Available from:

https://en.wikipedia.org/w/index.php?title $=\mathrm{Br}$ itish_Association_of_Physicians_of_Indian_Origi n\&oldid=954594994

10. Kaffash J. RCGP vows to take action on MRCGP failure rates after High Court ruling [Internet]. Pulse Today. [cited 2020 Aug 6]. Available from: http://www.pulsetoday.co.uk/news/gptopics/education/rcgp-vows-to-take-actionon-mrcgp-failure-rates-after-high-courtruling/20006403.article

11. Data \& research [Internet]. [cited 2020 Aug 6]. Available from: https://www.gmcuk.org/education/standards-guidance-andcurricula/projects/differentialattainment/data-and-research

12. Woolf K. Fair Training Pathways for All: Understanding Experiences of Progression Final Report. : 69.

13. Rimmer A. RCP is to highlight gap in performance between overseas doctors and UK graduates. BMJ [Internet]. 2014 Dec 2 [cited 2020 Aug 6];349. Available from: https://www.bmj.com/content/349/bmj.g744 1

14. Racism, health and why we must do more [Internet]. RCP London. 2020 [cited 2020 Aug 6]. Available from: https://www.rcplondon.ac.uk/news/racismhealth-and-why-we-must-do-more

Authors declare no conflict of Interest 